\title{
Advanced Glycation End Products Impair Voltage-Gated K+ Channels-Mediated Coronary Vasodilation in Diabetic Rats
}

\author{
Wen Su${ }^{1}$, Weiping $\mathrm{Li}^{1}{ }^{*}$, Hui Chen ${ }^{1}$, Huirong Liu ${ }^{2}$, Haixia Huang ${ }^{2}$, Hongwei $\mathrm{Li}^{1}{ }^{*}$ \\ 1 Department of Cardiology, Beijing Friendship Hospital, Capital Medical University, Beijing, PR China, \\ 2 Department of Physiology and Pathophysiology, School of Basic Medical Sciences, Capital Medical \\ University, Beijing, PR China
}

*Ihw19656@sina.com (HWL); xueer_09@126.com (WPL)

\section{G open access}

Citation: Su W, Li W, Chen H, Liu H, Huang H, Li H (2015) Advanced Glycation End Products Impair Voltage-Gated K+ Channels-Mediated Coronary Vasodilation in Diabetic Rats. PLoS ONE 10(11): e0142865. doi:10.1371/journal.pone.0142865

Editor: Ram Nagaraj, University of Colorado Denver School of Medicine, UNITED STATES

Received: August 8, 2015

Accepted: October 27, 2015

Published: November 12, 2015

Copyright: $\odot 2015$ Su et al. This is an open access article distributed under the terms of the Creative Commons Attribution License, which permits unrestricted use, distribution, and reproduction in any medium, provided the original author and source are credited.

Data Availability Statement: All relevant data are within the paper.

Funding: This work was supported by National Natural Science Foundation of China (Project 30971240) to Li.H, Beijing Natural Science Foundation Program (7122053) to Li.H, and Highlevel Technical Talents Foundation in Beijing Health System (No. 2013-3-060) to Li.W. The funders had no role in study design, data collection and analysis, decision to publish, or preparation of the manuscript.

Competing Interests: The authors have declared that no competing interests exist.

\section{Abstract}

\section{Background}

We have previously reported that high glucose impairs coronary vasodilation by reducing voltage-gated $\mathrm{K}^{+}\left(\mathrm{K}_{\mathrm{v}}\right)$ channel activity. However, the underlying mechanisms remain unknown. Advanced glycation end products (AGEs) are potent factors that contribute to the development of diabetic vasculopathy. The aim of this study was to investigate the role of AGEs in high glucose-induced impairment of $\mathrm{K}_{\mathrm{v}}$ channels-mediated coronary vasodilation.

\section{Methods}

Patch-clamp recording and molecular biological techniques were used to assess the function and expression of $\mathrm{K}_{\mathrm{v}}$ channels. Vasodilation of isolated rat small coronary arteries was measured using a pressurized myograph. Treatment of isolated coronary vascular smooth muscle cells (VSMCs) and streptozotocin-induced diabetic rats with aminoguanidine, the chemical inhibitor of AGEs formation, was performed to determine the contribution of AGEs.

\section{Results}

Incubation of VSMCs with high glucose reduced $\mathrm{K}_{\mathrm{v}}$ current density by $60.4 \pm 4.8 \%$, and decreased expression of $\mathrm{K}_{\mathrm{v}} 1.2$ and $\mathrm{K}_{\mathrm{v}} 1.5$ both at the gene and protein level, whereas inhibiting AGEs formation or blocking AGEs interacting with their receptors prevented high glucose-induced impairment of $\mathrm{K}_{\mathrm{v}}$ channels. In addition, diabetic rats manifested reduced $\mathrm{K}_{\mathrm{v}}$ channels-mediated coronary dilation $(9.3 \pm 1.4 \%$ vs. $36.9 \pm 1.4 \%, P<0.05)$, which was partly corrected by the treatment with aminoguanidine $(24.4 \pm 2.2 \%$ vs. $9.3 \pm 1.4 \%$, $P<0.05)$.

\section{Conclusions}

Excessive formation of AGEs impairs $\mathrm{K}_{\mathrm{v}}$ channels in VSMCs, then leading to attenuation of $\mathrm{K}_{\mathrm{v}}$ channels-mediated coronary vasodilation. 


\section{Background}

Cardiovascular diseases are the primary causes of morbidity and mortality among patients with diabetes. It has been characterized that in conduit arteries, vascular dysfunction is largely due to the loss of modulatory role of the endothelium [1]. In contrast, vascular smooth muscle cells (VSMCs) have been reported to play a predominant role in the regulation of vascular tone for the microcirculation [2,3]. $\mathrm{K}^{+}$channels in VSMCs take the principal responsibility for maintaining resting membrane potential and regulating smooth muscle tones [4]. We have previously demonstrated that voltage-gated $\mathrm{K}^{+}\left(\mathrm{K}_{\mathrm{v}}\right)$ channels, especially the $\mathrm{K}_{\mathrm{v}} 1$ "Shaker-type" family, take responsibility for coronary vasodilation in rat small coronary arteries (RSCAs) $[5,6]$. $K_{v}$ channels are involved in a number of physiological processes, including cAMP-dependent vasodilation [5,7]. Changes in the expression or activity of $\mathrm{K}_{\mathrm{v}}$ channels often translate into a variety of vascular diseases including atherosclerosis [8], systemic and pulmonary hypertension [9,10], and especially diabetic vasculopathy [11]. In these diseases, $\mathrm{K}_{\mathrm{v}}$ impairments associated with depolarizing shifts in VSMCs often result in a hypersensitivity to vasoconstrictor substances and increased level of vascular tone. Despite the importance of $\mathrm{K}_{\mathrm{v}}$ channels in modulating vascular tone, mechanisms involved in impaired $\mathrm{K}_{\mathrm{v}}$-mediated coronary microcirculation in diabetes remain poorly defined [5].

Advanced glycation end products (AGEs) are a group of cross-linked derivatives that are formed irreversibly in serum or tissues via non-enzymatic chemical reactions, due to hyperglycemia and oxidative stress [12]. There is accumulating evidence of the causal role for AGEs in the development of diabetic vasculopathy $[13,14,15,16]$. AGEs exert effects mainly by interacting with specific cell surface receptors, called receptor of advanced glycation products (RAGE) [17]. AGEs/RAGE axis increases inflammation and oxidative stress in many cell types including VSMCs, leading to vascular damage [18]. Retardation of AGEs formation with aminoguanidine (AG), the most extensively studied inhibitor of AGEs formation, has previously been shown to prevent diabetic vascular damage $[19,20]$. However, limited studies of the relationship between AGEs and altered $\mathrm{K}_{\mathrm{v}}$ channel function have been conducted in the coronary VSMCs.

The aim of our study is to investigate whether AGEs would impair the activity and expression of $\mathrm{K}_{\mathrm{v}}$ channels in VSMCs, and to further explore the role of AGEs in $\mathrm{K}_{\mathrm{v}}$-mediated coronary dysfunction in diabetic animals.

\section{Methods}

\section{Cell treatment}

Primary rat coronary VSMCs were isolated according to published methods [21], and incubated in Dulbecco's modified Eagle's medium (DMEM, Gibco, USA) containing 10\% fetal bovine serum (Gibco, USA), $100 \mathrm{U} / \mathrm{mL}$ penicillin, $100 \mathrm{mg} / \mathrm{mL}$ streptomycin, and $200 \mathrm{mmol} / \mathrm{L}$ L-glutamine for $48 \mathrm{~h}$ at $37^{\circ} \mathrm{C}$. Cells were pretreated with AG $(10 \mathrm{mmol} / \mathrm{L})$, or anti-RAGE IgG $(100 \mu \mathrm{g} /$ $\mathrm{mL}$ ), the RAGE neutralizing antibody, or vehicle for $30 \mathrm{~min}$ before incubation with $5.6 \mathrm{mmol} / \mathrm{L}$ (normal glucose) or $23 \mathrm{mmol} / \mathrm{L}$ (high glucose) $\mathrm{D}$-glucose. To investigate the direct effect of AGEs, VSMCs were pretreated with anti-RAGE IgG $(100 \mu \mathrm{g} / \mathrm{mL})$ or vehicle for $30 \mathrm{~min}$ before stimulation with $100 \mathrm{ug} / \mathrm{mL}$ AGE-BSA for $48 \mathrm{~h}$. The dose-dependent effect and osmotic influence of high glucose on coronary VSMCs have been previously evaluated [5,6,22,23], and the glucose concentration of $23 \mathrm{mmol} / \mathrm{L}$ was fixed for the following experiments. The concentrations of AGE-BSA and AG used were based on previous published studies [24,25].

\section{Animals}

Six-week-old male Sprague-Dawley rats (Vital River, Beijing, China) weighing 180 to 200 grams were housed as described previously [23]. The rats were randomly divided into two 
parts in the beginning of the study. The controls were fed with regular chow ( $13 \mathrm{kcal} \%$ fat) for 4 weeks and injected with citrate buffer alone. Other rats received high-fat diet $(58 \mathrm{kcal} \%$ fat with sucrose; Research Diets) for 4 weeks and then a single intraperitoneal injection of streptozocin $(25 \mathrm{mg} / \mathrm{kg}$, freshly prepared in $100 \mathrm{mmol} / \mathrm{L}$ citrate buffer, $\mathrm{pH} 4.5)$ after an overnight fast. Rats with blood glucose $>16.7 \mathrm{mmol} / \mathrm{L}$ were considered to have diabetes [26,27]. Diabetic rats were treated with 1-3 U/day of insulin to prevent ketoacidosis. The rats were divided into four groups: control $(n=8)$, diabetes (DM, $n=8)$, control + AG $(n=8)$, or diabetes + AG (DM $+\mathrm{AG}, n=8)$. The AG groups received $100 \mathrm{mg} / \mathrm{kg} /$ day AG dissolved in drinking water for 10 weeks. Animal protocols were based on the National Institutes of Health guidelines for care and use of laboratory animals, and approved by the Animal Care and Use Committee of Capital Medical University.

\section{Preparation of RSCAs and isometric force measurements}

Rats were anesthetized with an intraperitoneal injection of sodium pentobarbital (60 mg/kg). RSCAs (internal diameter 150-200 $\mu \mathrm{m}$ ) were dissected from the left ventricle and cut into 2 $\mathrm{mm}$ long rings. The endothelium was denuded with dry air. The efficacy of endothelial denudation was verified as previously reported [5]. The arterial rings were threaded on two stainless steel wires ( $40 \mu \mathrm{m}$ in diameter) and mounted in $5 \mathrm{ml}$ chambers of a multi wire myograph system (Model 610M, Danish Myo Technology, Aarhus, Denmark) filled with salt solution as previously described [5]. The physiological salt solution was continuously bubbled with $95 \% \mathrm{O}_{2}$ and $5 \% \mathrm{CO}_{2}$, and warmed to $37^{\circ} \mathrm{C}$. Tension signals were attached to a PowerLab recording unit and saved to a Chart 7 for Windows software (AD Instruments Ltd, Aarhus, Denmark). After being mounted, the vessels were equilibrated for $1 \mathrm{~h}$ before normalization. The passive tension-internal circumference was determined by stretching to a transmural pressure of 60 $\mathrm{mmHg}$ as previously reported [6]. Vessels were precontracted with the thromboxane $\mathrm{A}_{2}$ analog $\mathrm{U}-46619(10 \mathrm{nmol} / \mathrm{L})$. Forskolin, an adenylyl cyclase activator, was used for eliciting cAMPmediated vasodilation $[5,28]$. Dilations to forskolin $\left(10^{-10}-10^{-6} \mathrm{~mol} / \mathrm{L}\right)$ were compared in arterial rings before and after the application of 4-aminopyridine (4-AP), a selective blocker of $\mathrm{K}_{\mathrm{v}}$ channels. 4-AP ( $3 \mathrm{mmol} / \mathrm{L})$ was added to the chambers and incubated for $20 \mathrm{~min}$ before doseresponse curves were recorded.

\section{Patch-Clamp recording of $\mathrm{K}^{+}$Currents}

Standard pulse protocols were used to assess the whole-cell and voltage-gated $\mathrm{K}^{+}$currents as detailed previously [5]. Briefly, $\mathrm{K}^{+}$currents were generated by a series of $400 \mathrm{~ms}$ depolarizing pulses from $-60 \mathrm{mV}$ to $+60 \mathrm{mV}$ in $10 \mathrm{mV}$ increments. $\mathrm{K}_{\mathrm{Ca}}$ currents were minimized by using recording solutions with a low $\mathrm{Ca}^{2+}$ concentration $(10 \mathrm{nmol} / \mathrm{L})$ and adding $100 \mathrm{nmol} / \mathrm{L}$ iberiotoxin in the bath solution. Seal resistance was 2 to $10 \mathrm{G} \Omega$. $\mathrm{K}_{\mathrm{v}}$ current was defined by subtracting outward currents recorded in the presence of $3 \mathrm{mmol} / \mathrm{L} 4-\mathrm{AP}$ from outward currents recorded in drug-free bath solution. Current density of $\mathrm{K}_{\mathrm{v}}$ channels was calculated to normalize for cellular membrane area. Hyperpolarizing steps of $10 \mathrm{mV}$ were averaged to measure cell capacitances and leak compensation values. Membrane currents were recorded with an EPC-9 amplifier and Pulse software (Heka Elektronik, Germany). Pulses were generated by a digitalto-analog converter controlled by Pulse software.

\section{Detection of AGEs}

Serum samples and culture media were collected and AGEs levels were analyzed using an AGEs ELISA kit (MyBioSource, USA) according to the manufacturer's instruction. 


\section{Western blotting}

Western blotting in VSMCs and coronary tissues was performed as previously reported [29]. The following antibodies were used: anti- $\mathrm{K}_{\mathrm{v}} 1.2$, anti- $\mathrm{K}_{\mathrm{v}} 1.5$, anti-RAGE, and anti- $\beta$-actin (all from Abcam, U.K.).

\section{Quantitative real-time (RT)-PCR}

RNA isolation and CDNA generation were done as described previously [23]. Gene expression of $\mathrm{K}_{\mathrm{v}} 1.2$ and $\mathrm{K}_{\mathrm{v}} 1.5$ was assessed by quantitative RT-PCR. Primers used were as follows: $\mathrm{K}_{\mathrm{v}} 1.2$ sense $5^{\prime}$-CATTTTGTACTACTACCAGTC- ${ }^{\prime}$, antisense $5^{\prime}$-GGAGTGTCTGGACAACTTGA$3^{\prime} ; \mathrm{K}_{\mathrm{v}} 1.5$ sense $5^{\prime}$-TGAGCAGGAGGGGAATCAGA- $3^{\prime}$, antisense $5^{\prime}$-ACACCCTTACCAA GCGGATG- $3^{\prime}$; $\beta$-actin sense $5^{\prime}$-CCCATCTATGAGGGTTACGC- ${ }^{\prime}$, antisense $5^{\prime}$-TTTA ATGTCACGCACGATTTC- $3^{\prime} . \Delta \triangle$ CT values were calculated as previously described [23]. Gene expression was normalized with $\beta$-actin and reported as ratios compared with the level of expression in untreated control group, which was given an arbitrary value of 1 .

\section{Chemicals}

AGE-BSA for VSMCs incubation was purchased from Merck Millipore. Endotoxin levels were found to be less than $0.8 \mathrm{EU} / \mathrm{mg}$ protein with the Limulus amebocyte assay (E-Toxate kit, Sigma, USA). Anti-RAGE IgG was from R\&D system (Minneapolis, USA). All the other chemicals were purchased from Sigma (St Louis, USA).

\section{Statistical analysis}

The presented values were expressed as mean \pm SD. Comparisons among different groups were performed by one-way ANOVA followed by Bonferroni test. The significance was regarded as $P<0.05$.

\section{Results}

\section{AGEs are required for high glucose-induced $\mathrm{K}_{\mathrm{v}}$ channel dysfunction in VSMCs}

VSMCs were incubated with AG, followed by high glucose treatment for $48 \mathrm{~h}$. As Fig $1 \mathrm{~A}$ shows, AGEs were increased to approximately twofold by treatment with high glucose. In contrast, AG blunted the production of AGEs. Fig $1 \mathrm{~B}$ and $1 \mathrm{C}$ show sample traces of whole cell $\mathrm{K}^{+}$ currents generated by $10-\mathrm{mV}$ incremental depolarizing steps from -60 to $+60 \mathrm{mV}$ in VSMCs from RSCAs. Current-voltage relations averaged from six cells verified that high glucose reduced $\mathrm{K}_{\mathrm{v}}$ current density by $60.4 \pm 4.8 \%$, whereas AG prevented the high glucose-induced impairment on $\mathrm{K}_{\mathrm{v}}$ activity by $56.9 \pm 7.8 \%$ (Fig $1 \mathrm{~B}$ and $1 \mathrm{C}$ ). Treatment with $\mathrm{AG}$ had no obvious effect on $\mathrm{K}_{\mathrm{v}}$ activity in normal glucose-incubated cells.

Given the role of RAGE in AGEs-induced intracellular signaling cascades, the role of RAGE in $\mathrm{K}_{\mathrm{v}}$ dysfunction was also investigated. VSMCs were pretreated with anti-RAGE IgG, before treatment with high glucose. Expression of RAGE was increased by high glucose treatment as compared with normal glucose group, whereas anti-RAGE IgG prominently decreased available RAGE for AGEs to bind (Fig 1D). Patch clamp results showed that anti-RAGE reversed the high glucose-induced suppression of $\mathrm{K}_{\mathrm{v}}$ current density by $69.3 \pm 9.5 \%$ (Fig $1 \mathrm{~B}$ and $1 \mathrm{C}$ ). These data suggest that high glucose-reduced $\mathrm{K}_{\mathrm{v}}$ current density in VSMCs is mainly mediated via AGEs. 

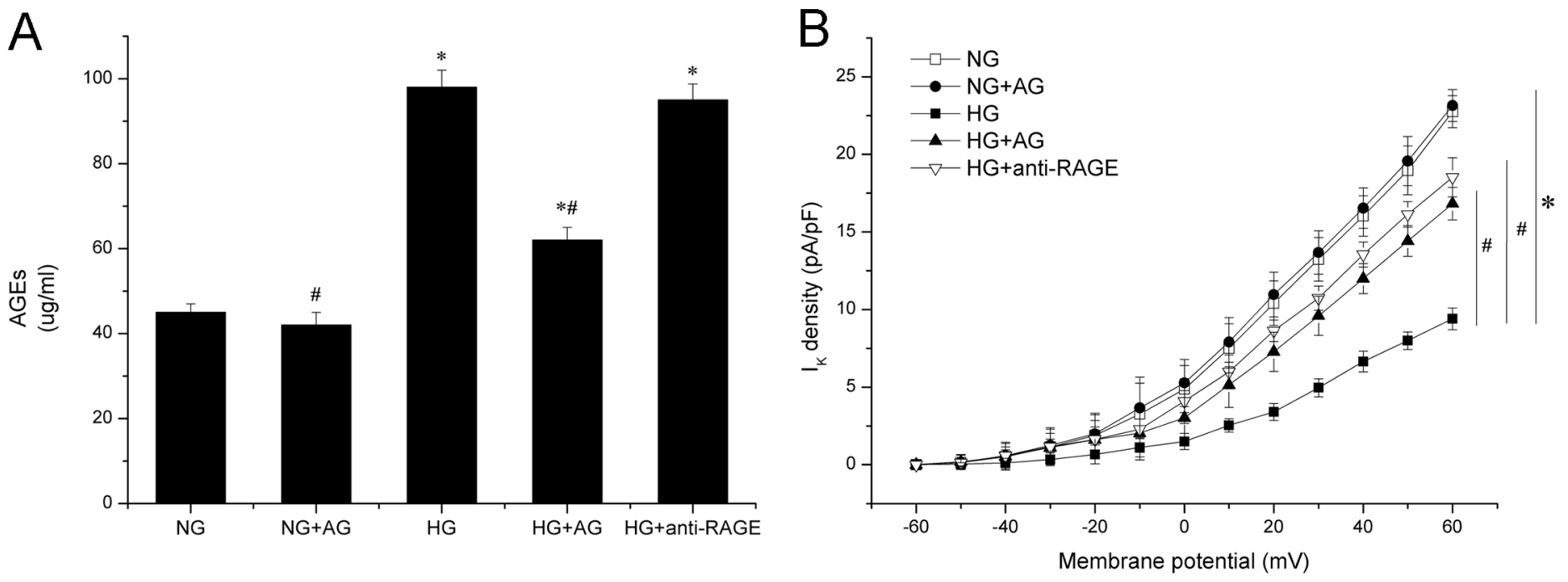

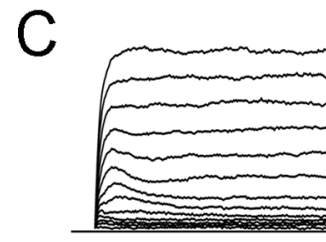

NG

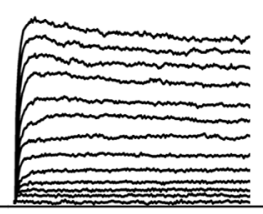

$N G+A G$

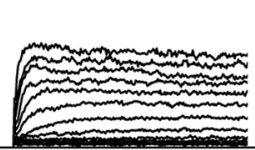

HG

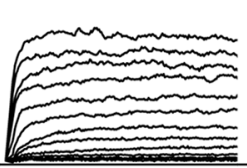

$H G+A G$

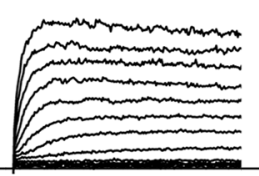

HG+anti-RAGE

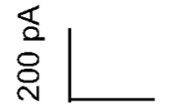

$100 \mathrm{~ms}$

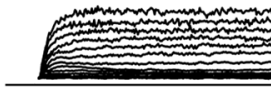

NG

$+4-\mathrm{AP}$

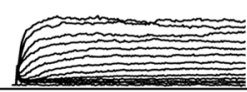

$N G+A G$

$+4-\mathrm{AP}$

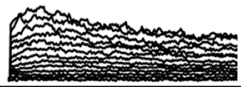

HG

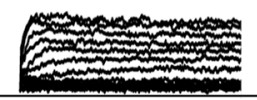

$H G+A G$

$+4-A P$

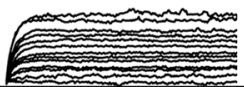

HG+anti-RAGE

+ 4-AP

$+60 \mathrm{mv}, 400 \mathrm{~ms}$

$\mathrm{D}$
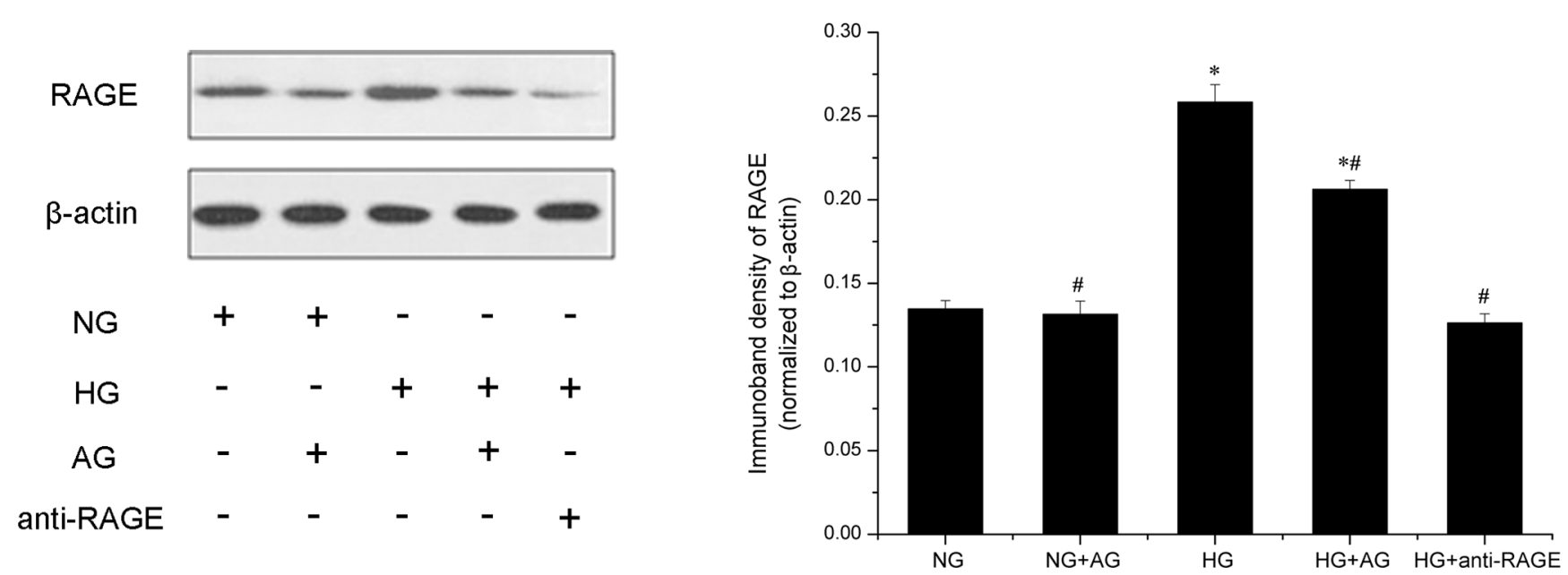

Fig 1. The role of AGEs in high glucose-induced voltage-gated $\mathrm{K}^{+}\left(\mathrm{K}_{\mathrm{v}}\right)$ channels dysfunction in vascular smooth muscle cells (VSMCs). $A$ :

Overproduction of AGEs in high glucose was blunted by treatment with aminoguanidine (AG). B: I-V relationships of $\mathrm{K}_{\mathrm{v}}$ current density in VSMCs. $n=6$ for independent cells in each group. C: Sample traces of whole cell $\mathrm{K}^{+}$currents recorded before and after incubation with $3 \mathrm{mmol} / \mathrm{L} 4$-aminopyridine (4-AP). $\mathrm{K}^{+}$ currents were generated by $10-\mathrm{mV}$ incremental depolarizing steps from -60 to $+60 \mathrm{mV}$. D: Expression of receptor of advanced glycation products (RAGE) was determined by western blotting. Pretreatment with anti-RAGE decreased available RAGE for AGEs to bind. ${ }^{*} P<0.05 \mathrm{vs}$. normal glucose (NG). $\# P<0.05$ vs. high glucose (HG). 


\section{AGEs mediate high glucose-induced downregulation of $\mathrm{K}_{\mathrm{v}}$ channel expression}

The change of high glucose-induced $\mathrm{K}_{\mathrm{v}}$ channel expression was further investigated. VSMCs were incubated with AG, followed by high glucose treatment, and the expression of $\mathrm{K}_{\mathrm{v}} 1.2$ and $\mathrm{K}_{\mathrm{v}} 1.5$ was evaluated by RT-PCR and western blot analysis. As Fig 2 shows, high glucose significantly decreased expression of $\mathrm{K}_{\mathrm{v}} 1.2$ and $\mathrm{K}_{\mathrm{v}} 1.5$ at the gene and protein level, as compared with normal glucose group. Treatment with AG prevented high glucose-induced impairment of $\mathrm{K}_{\mathrm{v}} 1.2$ expression. Additionally, anti-RAGE reversed the change of $\mathrm{K}_{\mathrm{v}} 1.2$ observed in high glucose, approaching the level observed in control. The expression of $\mathrm{K}_{\mathrm{v}} 1.5$ was also increased in $\mathrm{AG}$ and anti-RAGE groups at the gene and protein level, as compared with high glucose group, suggesting that AGEs are required for high glucose-induced impairment of $\mathrm{K}_{\mathrm{v}} 1.2$ and $\mathrm{K}_{\mathrm{v}} 1.5$ expression.

\section{AGEs impair $\mathrm{K}_{\mathrm{v}}$ current and expression via interacting with RAGE}

To further establish a role for AGEs in high glucose-induced $\mathrm{K}_{\mathrm{v}}$ impairment, a direct effect of AGEs on $\mathrm{K}_{\mathrm{v}}$ channels was investigated. VSMCs were pretreated with anti-RAGE or vehicle before treatment with AGE-BSA. AGE-BSA was incubated with VSMCs for $48 \mathrm{~h}$ followed by patch clamp, RT-PCR and western blot analysis. Treatment with AGEs was associated with a $34 \%$ reduction of $\mathrm{K}_{\mathrm{v}}$ current density compared with control (Fig $3 \mathrm{~A}$ and $3 \mathrm{~B}$ ). $\mathrm{K}_{\mathrm{v}} 1.5$ channel expression at the gene and protein level was significantly decreased (Fig $3 \mathrm{C}$ and $3 \mathrm{D}$ ). $\mathrm{K}_{\mathrm{v}} 1.2$ also appeared reduced after AGEs treatment, as compared with control, albeit with a less dramatic change than $\mathrm{K}_{\mathrm{v}} 1.5$. Pretreatment with anti-RAGE blocked these modifications caused by AGEs, indicating that AGEs, independent of glucose concentrations, can impair $\mathrm{K}_{\mathrm{v}}$ current and expression via interacting with RAGE.

\section{$\mathrm{K}_{\mathrm{v}}$ channels-mediated coronary dilation is impaired in diabetic rats}

Diabetes-induced impairment of $\mathrm{K}_{\mathrm{v}}$-mediated vasodilation in RSCAs was determined. Diabetic rats were confirmed and coronary arteries were isolated. Patch-clamp recording and molecular biological techniques revealed reduced $\mathrm{K}_{\mathrm{v}}$ current density and decreased expression of both $\mathrm{K}_{\mathrm{v}} 1.2$ and $\mathrm{K}_{\mathrm{v}} 1.5$ in diabetic rats $(P<0.05 v$ s. control, Fig $4 \mathrm{~A}, 4 \mathrm{~B}$ and $4 \mathrm{C})$, which was consistent with the results in vitro. RSCAs were mounted in an arteriograph. To exclude the potential role for endothelial involvement, coronary dilation was compared in the absence of endothelium. Fig 4D illustrates that forskolin elicited vasodilation of RSCAs in a dose-dependent manner. Maximal dilations to forskolin in RSCAs of diabetic rats were reduced (54.6 $\pm 1.6 \mathrm{vs}$. $91.1 \pm 2.1 \%, n=8$ for independent arterial rings in each group, $P<0.05 v s$. control). These results suggest that diabetes impairs vasodilation mediated by cAMP. Impaired cAMP-mediated dilation in DM can be explained by vascular changes independent of the endothelium.

The requirement for $\mathrm{K}_{\mathrm{v}}$ in diabetes-induced vascular dysfunction was further investigated. Maximal dilations to forskolin were reduced by $3 \mathrm{mmol} / \mathrm{L} 4-\mathrm{AP}$, suggesting that the cAMP-mediated dilation in these vessels is predominantly regulated by $\mathrm{K}_{\mathrm{v}}$ channels. 4-AP blocked vasodilation in both control and DM group. Moreover, the 4-AP-sensitive component of forskolininduced dilation in DM group was reduced $(9.3 \pm 1.4 \%$ vs. $36.9 \pm 1.4 \%, P<0.05 v$ s. control, Fig $4 \mathrm{E}$ ), suggesting that $\mathrm{K}_{\mathrm{v}}$ channels-mediated coronary dilation is impaired in diabetic rats.

\section{Diabetes-induced impairment of vasodilation requires AGEs formation in rat coronary microvessels}

To evaluate the effect of AGEs in vivo, diabetic rats were randomized to be treated with AG or vehicle. After 10 weeks, coronary arteries were harvested. As Table 1 shows, treatment with AG 

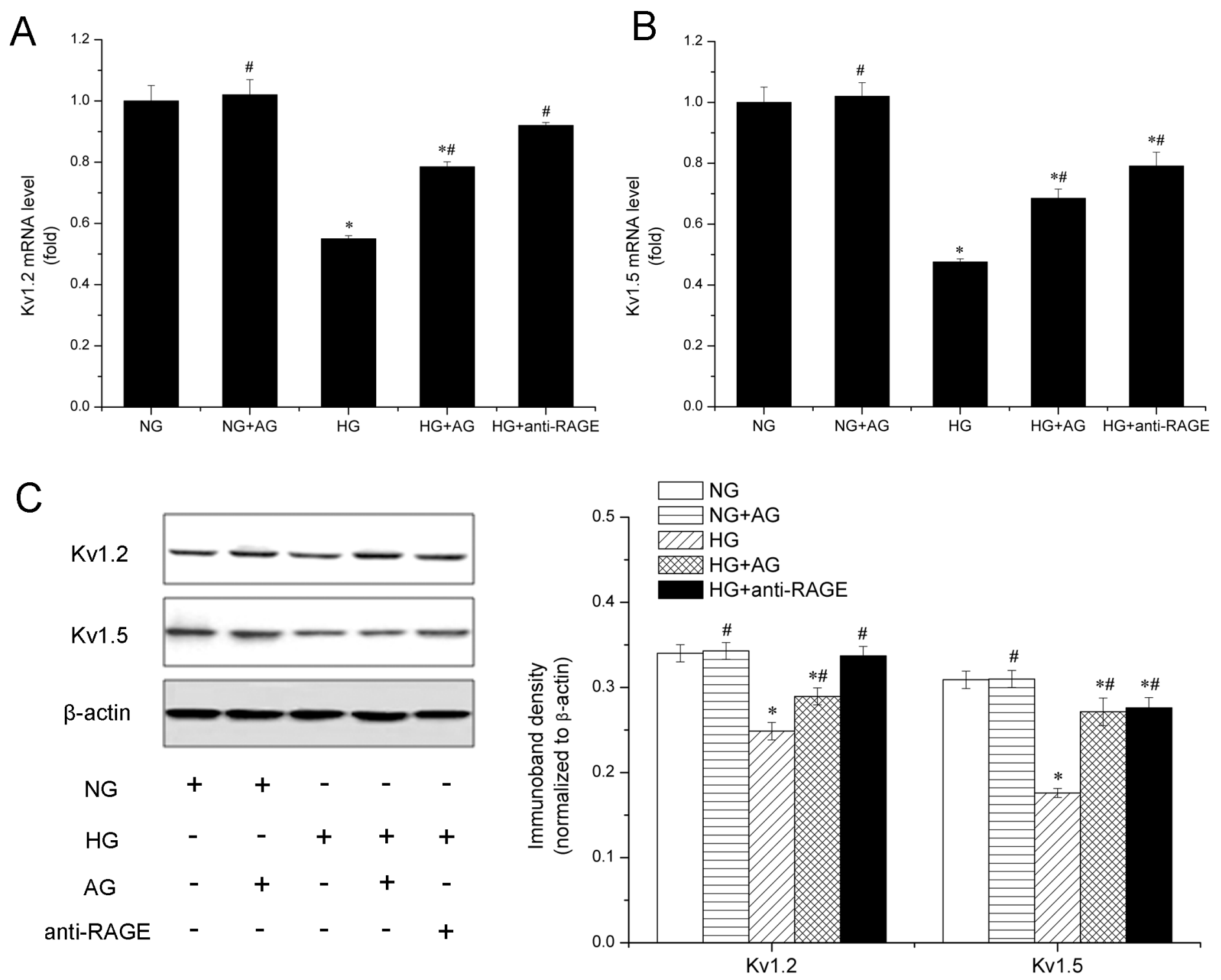

Fig 2. The role of AGEs in high glucose-induced downregulation of voltage-gated $\mathrm{K}^{+}\left(\mathrm{K}_{\mathrm{v}}\right)$ channels expression in vascular smooth muscle cells (VSMCs). VSMCs were incubated with Aminoguanidine (AG) or anti-receptor of advanced glycation products (RAGE) for 30 min, followed by high glucose treatment, and expression of $\mathrm{K}_{\mathrm{v}} 1.2$ and $\mathrm{K}_{\mathrm{v}} 1.5$ at the gene and protein level was evaluated by quantitative real-time-PCR (A and $\left.B\right)$ and western blot analysis (C). ${ }^{*} P<0.05$ vs. normal glucose (NG). \# $P<0.05$ vs. high glucose $(\mathrm{HG})$.

doi:10.1371/journal.pone.0142865.g002

had no effect on weight, blood pressure, and glucose level. However, AG decreased serum AGEs. Both function and expression of $\mathrm{K}_{\mathrm{v}}$ were increased by AG treatment, compared with the DM group (Fig 4A, 4B and 4C). In non-diabetic controls, although AG treatment lowered AGEs level, it failed to increase $\mathrm{K}_{\mathrm{v}}$ expression.

Forskolin-elicited relaxation was significantly altered in RSCAs from AG-treated diabetic rats compared to vehicle-treated diabetic rats, as assessed with a myograph. Maximal dilations to forskolin in RSCAs of AG-treated diabetic rats were improved (74.3 \pm 1.6 vs. $54.6 \pm 1.6 \%$, $n=8$ for independent arterial rings in each group, $P<0.05 v s$. DM, Fig 4D). In addition, AG treatment partially reversed the decrease of $\mathrm{K}_{\mathrm{v}}$-mediated coronary vasodilation $(24.4 \pm 2.2 \mathrm{vs}$. $9.3 \pm 1.4 \%, n=8$ for independent arterial rings in each group, $P<0.05 v s . \mathrm{DM}$, Fig $4 \mathrm{E})$. The 
A

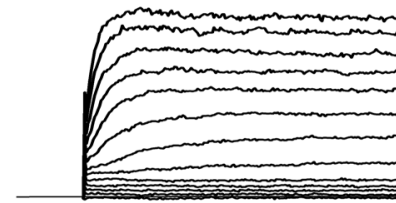

Control

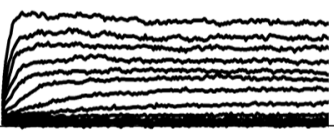

AGES

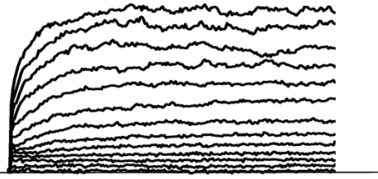

AGEs+anti-RAGE $\stackrel{\nwarrow}{\stackrel{a}{2}}$

$100 \mathrm{~ms}$

$+60 \mathrm{mv}, 400 \mathrm{~ms}$

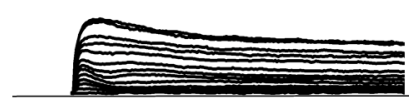

Control

$+4-\mathrm{AP}$

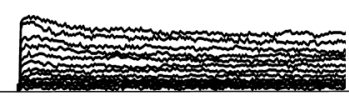

AGES

+ 4-AP

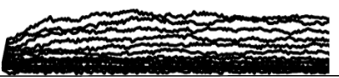

AGEs+anti-RAGE $+4-A P$

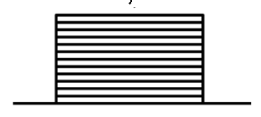

$-60 \mathrm{mv}$
B

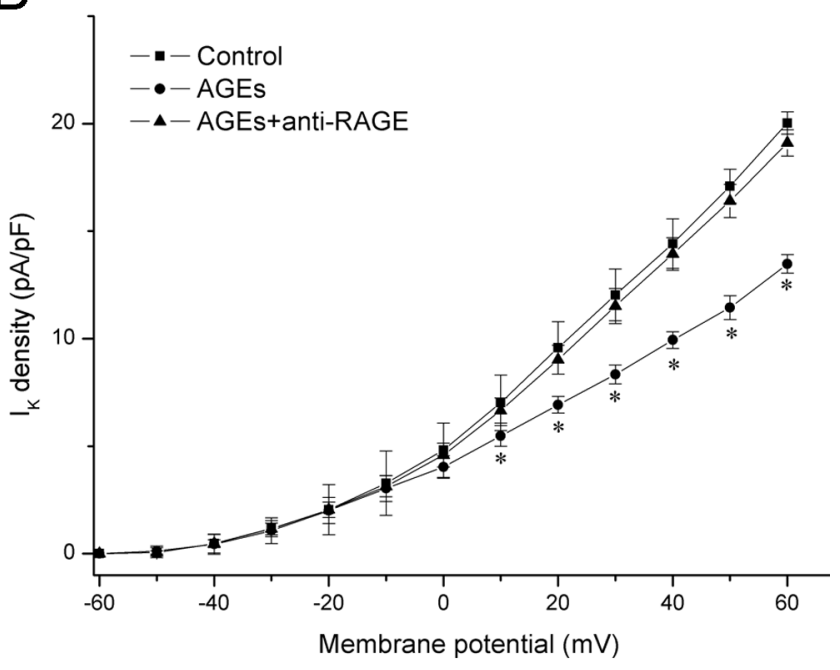

D

$\mathrm{Kv1.2}$

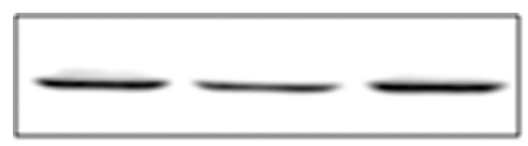

Kv1.5

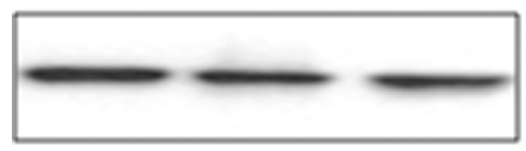

$\beta$-actin

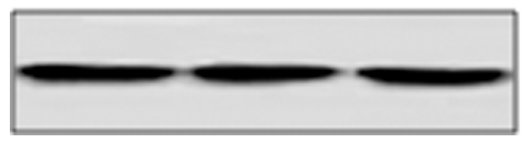

AGES

Control

AGES
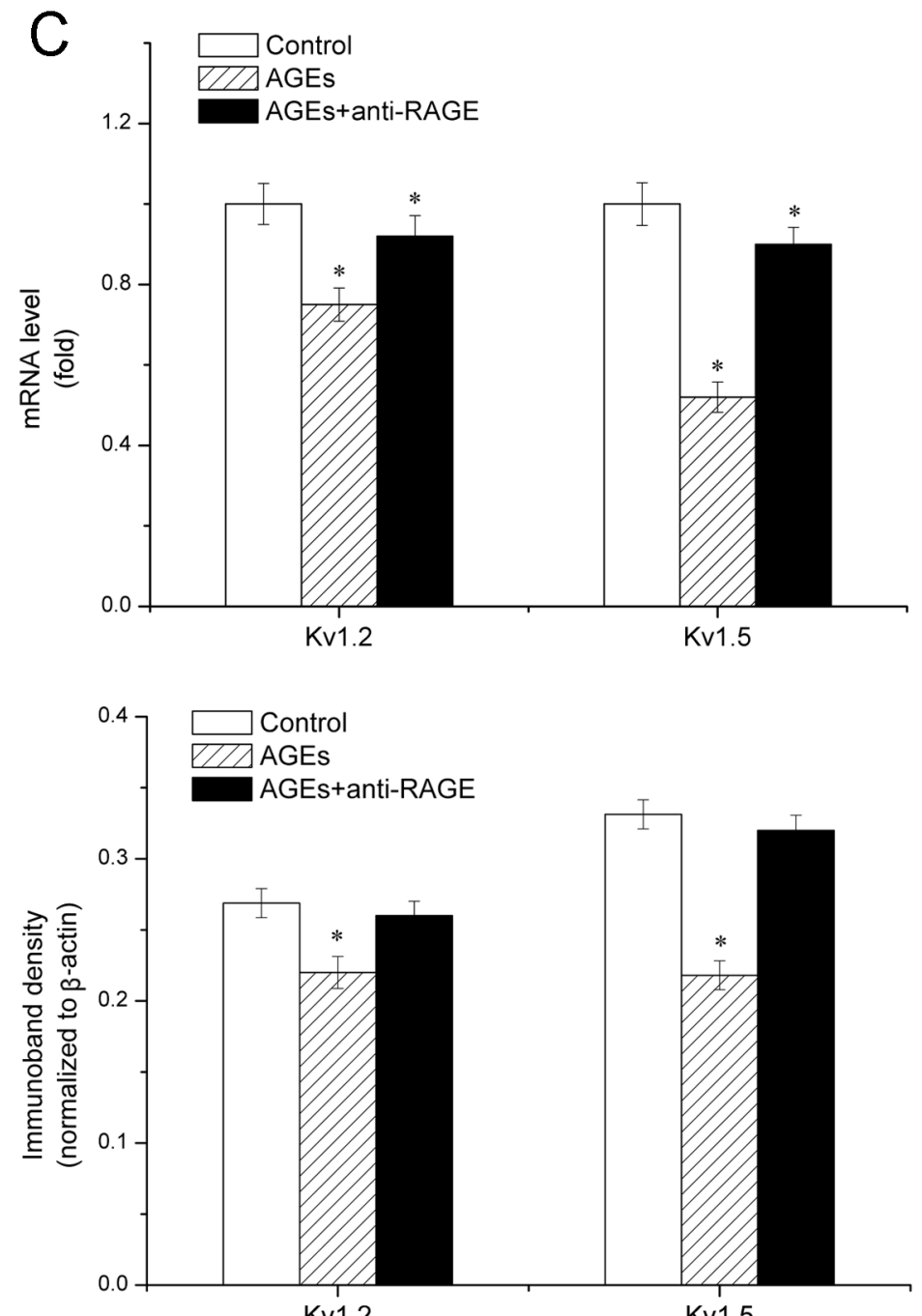

Kv1.2

Kv1.5

Fig 3. AGEs impair voltage-gated $\mathrm{K}^{+}\left(\mathrm{K}_{\mathrm{v}}\right)$ current and expression via interacting with receptor of advanced glycation products (RAGE). A: Sample traces of whole cell $\mathrm{K}^{+}$currents recorded before and after incubation with $3 \mathrm{mmol} / \mathrm{L} 4$-aminopyridine (4-AP). $\mathrm{K}^{+}$currents were generated by 10 -mV incremental depolarizing steps from -60 to $+60 \mathrm{mV}$. B: I-V relationships of $\mathrm{K}_{\mathrm{v}}$ current density in vascular smooth muscle cells. $n=6$ for independent cells in 
each group. C and D: After treatment with AGEs alone or AGEs plus anti-RAGE, expression of $\mathrm{K}_{\mathrm{v}} 1.2$ and $\mathrm{K}_{\mathrm{v}} 1.5$ at the gene and protein level was evaluated by quantitative real-time-PCR (C) and western blot analysis (D). ${ }^{*} P<0.05$ vs. Control.

doi:10.1371/journal.pone.0142865.g003

data shown above suggest that AGEs are upstream regulators for $\mathrm{K}_{\mathrm{v}}$ impairment, which mediates diabetes-induced reduction in coronary dilation.

\section{Discussion}

The aim of this study was to determine the mechanism of coronary dysfunction in response to diabetes, and in particular, the role of AGEs. High glucose reduced approximately half of the $\mathrm{K}_{\mathrm{v}}$ current density in VSMCs, whereas the reduction was almost prevented by AG, the chemical inhibitor of AGEs formation. Furthermore, AG prevented high glucose-induced impairment of $\mathrm{K}_{\mathrm{v}}$ expression. Finally in vivo data from diabetic rat coronary microvessels further support a role for AGEs in $\mathrm{K}_{\mathrm{v}}$-mediated coronary dysfunction. These studies strongly suggest that at least part of the coronary dysfunction in diabetes is mediated via impairment of $\mathrm{K}_{\mathrm{v}}$ channels and excessive formation of AGEs takes major responsibility in this process.

The present study demonstrate that AGEs impaired cAMP-mediated relaxation in rat coronary microvessels and the mechanism involved impairment of $\mathrm{K}_{\mathrm{v}}$ channels in VSMCs. $\mathrm{K}_{\mathrm{v}}$ channels have been previously shown to be impaired in various pathologic conditions, such as hypertension [10], and hypercholesterolemia [30]. Some of the effects observed in DM rats can be due to other factors, such as the raised blood pressure. However, exposure of VSMCs to AGE-BSA in vitro could directly evaluate the effect of AGEs on $\mathrm{K}_{\mathrm{v}}$ channels without confounding influences in vivo. Patch clamp studies revealed that AGEs reduced a 4-AP sensitive component of $\mathrm{K}^{+}$current, suggesting that $\mathrm{K}_{\mathrm{v}}$ channels are susceptible to AGEs inhibition. In addition, our data showed that AGEs downregulated $\mathrm{K}_{\mathrm{v}} 1.2$ and $\mathrm{K}_{\mathrm{v}} 1.5$ expression at the gene and protein level. Our previous study presented that short-term exposure of RSCAs to high glucose for $24 \mathrm{~h}$ enhanced nitration of $\mathrm{K}_{\mathrm{v}}$ channels without changing the expression of $\mathrm{K}_{\mathrm{v}} 1.2$ and $\mathrm{K}_{\mathrm{v}} 1.5$ [6]. The difference between these two results may be ascribed to the different methods and exposure time. Incubation of RSCAs in vitro may not produce the same degree of stimulation to $\mathrm{K}_{\mathrm{v}}$ channels as in direct incubation of VSMCs. Our results are consistent with a model in which AGEs downregulated the expression of $\mathrm{K}_{\mathrm{Ca}} 2.3$ and $\mathrm{K}_{\mathrm{Ca}} 3.1$ channels in human umbilical vein endothelial cells and damaged $\mathrm{K}_{\mathrm{Ca}} 2.3$ and $\mathrm{K}_{\mathrm{Ca}} 3.1$-mediated relaxation in small mesenteric arteries [31]. Because $\mathrm{K}_{\mathrm{v}}$ channels are critical in vascular function [8,9], they represent potential therapeutic targets to restore normal levels of vascular reactivity.

Overproduction of AGEs has been reported to contribute to endothelial dysfunction in type 2 diabetes. A previous study by Gao and coworkers showed that impaired coronary vasodilator response to acetylcholine was restored by blockade of AGEs/RAGE [13]. AGEs-induced inactivation of nitric oxide and impairment of endothelium-dependent vasodilation were also seen in rat aortas [1] and mesenteric resistance arteries [14]. Here, we further examined the mechanism of AGEs-mediated vascular dysfunction, focusing on the potential role of endotheliumindependent vasodilation. The mechanical force leading to vasoconstriction is exerted by smooth muscle cells, which were reported to play a predominant role in the regulation of pressure-induced vasodilation [32]. We previously compared coronary dilation to forskolin in the presence and absence of endothelium. Endothelial denudation did not reduce dilation to forskolin. Furthermore, the reduction in forskolin-induced dilation in high glucose was similar in intact and denuded vessels [5]. The results presented herein further strengthen this link and suggest that overproduction of AGEs in high glucose environment leads to the impairment of $\mathrm{K}_{\mathrm{v}}$ channels, regulating endothelium-independent vasodilation. 
A

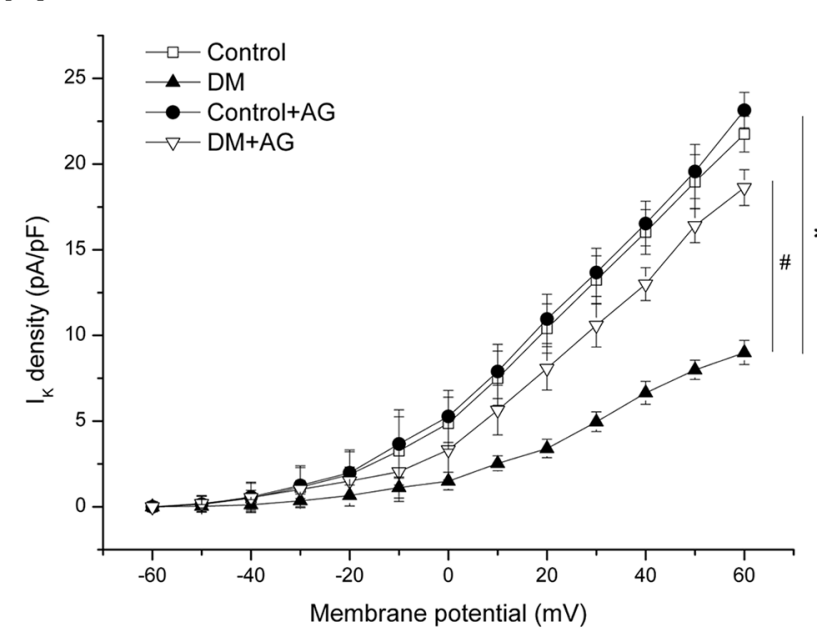

B

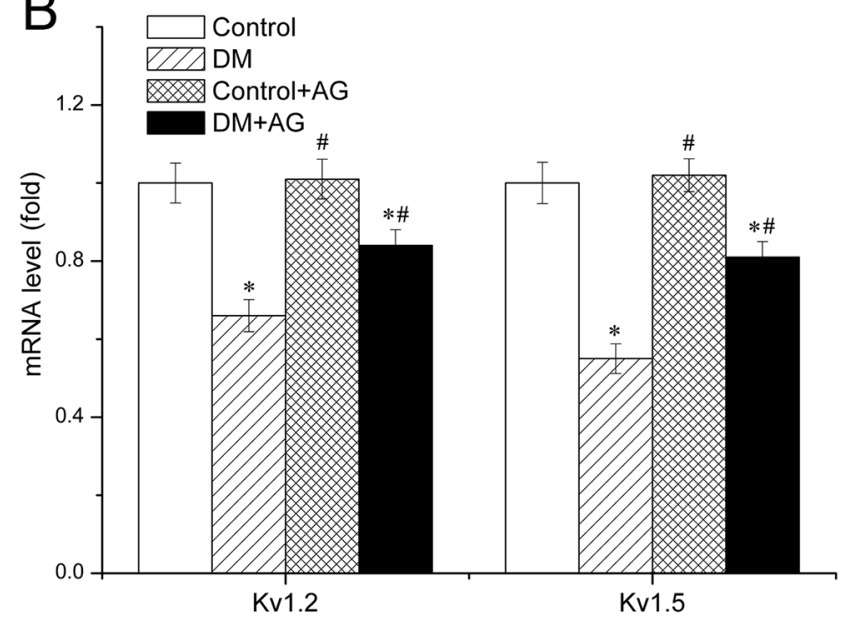

C
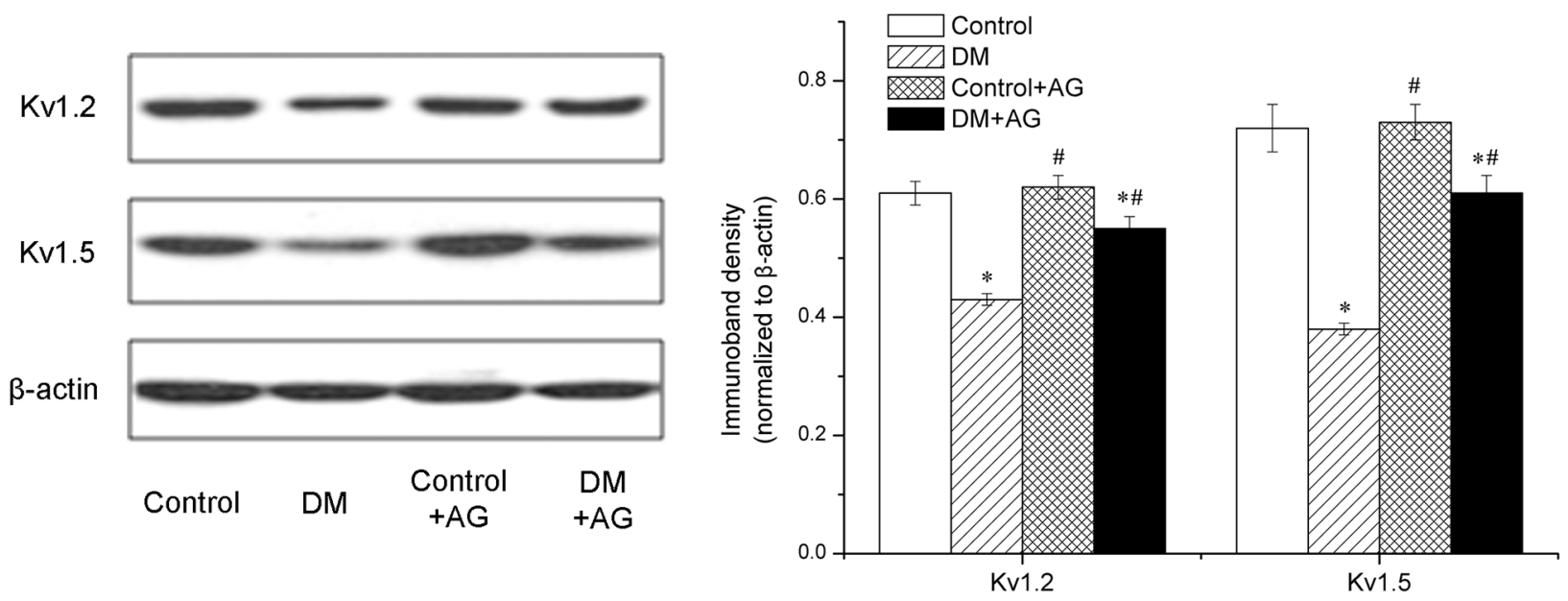

$\mathrm{D}$

$E$

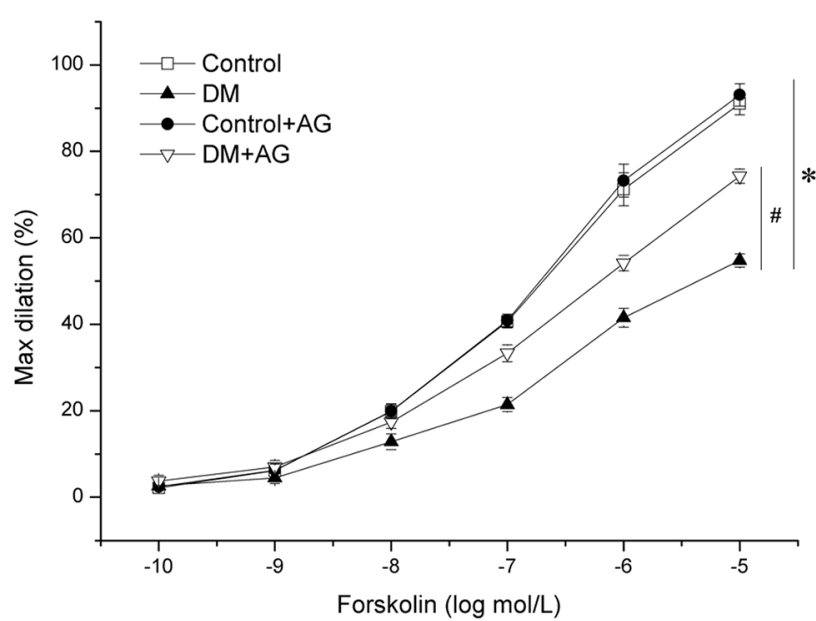

Fig 4. Role of AGEs in impaired $K_{v}$ channels-mediated coronary vasodilation in diabetic rats. Control and Diabetic rats were treated with aminoguanidine (AG) or vehicle for 10 weeks. Rat small coronary arteries (RSCAs) were isolated from different rat groups. A: $K_{v}$ current density in vascular smooth muscle cells isolated from different rat groups. $n=6$ for independent cells in each group. $\mathrm{B}$ and $\mathrm{C}$ : Expression of $\mathrm{K}_{\mathrm{v}} 1.2$ and $\mathrm{K}_{\mathrm{v}} 1.5$ at the gene and protein level was evaluated by quantitative real-time-PCR (B) and western blot analysis (C). D: Dose-dependent dilation to forskolin in RSCAs was measured using a pressurized myograph. E: After incubation of RSCAs with $3 \mathrm{mmol} / \mathrm{L} \mathrm{K}_{\mathrm{v}}$ inhibitor 4-aminopyridine (4-AP) for $20 \mathrm{~min}$, dilations to forskolin in all rat 
groups were significantly reduced. $\mathrm{K}_{\mathrm{v}}$ channels-mediated vasodilation was defined as the difference between dilations measured before and after incubation with 4-AP. $n=8$ for independent arterial rings in each group. ${ }^{*} P<0.05$ vs. Control. \# $P<0.05$ vs. diabetic group (DM).

doi:10.1371/journal.pone.0142865.g004

The AGEs/RAGE axis appears to play a major role in vascular dysfunction in diabetes $[33,34]$. In our study, RAGE expression was increased by high glucose treatment, which was consistent with previous studies showing that RAGE expression can be triggered by multiple molecular ligands including AGEs concomitantly present in high glucose incubation [22,35]. Since AGEs formation is a non-enzymatic reaction, both $\mathrm{K}_{\mathrm{v}} 1.2$ and $\mathrm{K}_{\mathrm{v}} 1.5$ under high glucose concentration may be glycated to form AGEs, and their glycation will surely impair the $\mathrm{K}_{\mathrm{v}}$ channels. However, AGEs have been reported to do their job both through direct and indirect ways [12]. In the former, AGEs exert bad effects via cross linking of important proteins. On the other hand, AGEs bind to RAGE, thereby inducing oxidative stress [18,36,37,38,39], leading to $\mathrm{K}_{\mathrm{v}}$ channel impairment and vascular damage $[6,40,41,42]$. Therefore, we used anti-RAGE to block AGEs binding with RAGE. As Fig 1 and Fig 2 show, pretreatment with anti-RAGE almost inhibited high glucose-induced impairment of $\mathrm{K}_{\mathrm{v}}$ channels without changing the level of AGEs. So, we conclude that the impairment of $\mathrm{K}_{\mathrm{v}} 1.2$ and 1.5 happens downstream of the binding of AGEs and RAGE. It seems unlike that $\mathrm{K}_{\mathrm{v}} 1.2$ and $\mathrm{K}_{\mathrm{v}} 1.5$ proteins are itself glycated by high glucose. This finding highlights that AGEs-induced $\mathrm{K}_{\mathrm{v}}$ impairment is primarily mediated through RAGE activation. Thus, inhibiting AGEs formation or blocking AGEs interacting with RAGE may be a potential therapeutic target for $\mathrm{K}_{\mathrm{v}}$-mediated coronary dysfunction in diabetic patients.

The interaction of AGEs/RAGE can activate a diverse array of intracellular signaling pathways including $\mathrm{p} 21^{\text {ras }}$, MAPK, and NF- $\mathrm{KB}$ that stimulate oxidative stress $[18,36,37,38,39]$. Increased oxidative stress has been described to downregulate $\mathrm{K}_{\mathrm{v}}$ channels both at the protein and mRNA level $[40,41,42]$. In addition, AGEs/RAGE interaction has been shown to downregulate PPAR $\gamma$, a member of the nuclear hormone receptor superfamily, which was proposed to be a regulator of transcriptional regulation of $\mathrm{K}_{\mathrm{v}}$ channel expression in retinal arterioles $[43,44]$. Expression and function of $\mathrm{K}_{\mathrm{v}}$ channels vary between different vascular tissues [45]. We previously reported that peroxynitrite, formed by the interaction of superoxide and nitric oxide, impaired $\mathrm{K}_{\mathrm{v}}$ channel function by nitrating the $\mathrm{K}_{\mathrm{v}}$ channel protein in coronary arterioles [6]. Therefore, we speculate that AGEs/RAGE-augmented oxidative stress may play a role in impaired $\mathrm{K}_{\mathrm{v}}$ channels in coronary vascular smooth muscle cells. However, further studies should be done to advance the understanding of mechanisms involved in AGEs/RAGE-downregulated $\mathrm{K}_{\mathrm{v}}$ channel expression.

Several limitations of this study should be acknowledged. First, other families of $\mathrm{K}_{\mathrm{v}}$ channels have also been shown to be expressed in VSMCs and might also be affected in this diabetic

Table 1. Clinical characteristics of control and diabetic rats.

\begin{tabular}{lcccc}
\hline & Control & DM & Control+AG & DM+AG \\
\hline Weight, g & $424.1 \pm 1.6$ & $395.1 \pm 1.8^{*}$ & $425.5 \pm 1.6^{\#}$ & $395.3 \pm 3.2^{*}$ \\
Systolic BP, $\mathrm{mmHg}$ & $124.0 \pm 1.3$ & $133.3 \pm 2.6^{*}$ & $125.0 \pm 1.9^{\#}$ & $131.3 \pm 2.5^{*}$ \\
Diastolic BP, $\mathrm{mmHg}$ & $84.5 \pm 1.9$ & $88.5 \pm 1.9^{*}$ & $84.6 \pm 1.9^{\#}$ & $88.0 \pm 1.6^{*}$ \\
Glucose, $\mathrm{mmol} / \mathrm{L}$ & $5.8 \pm 0.3$ & $23.4 \pm 1.6^{*}$ & $5.9 \pm 0.2^{\#}$ & $23.3 \pm 1.9^{*}$ \\
AGEs, $\mathrm{ug} / \mathrm{mL}$ & $49.8 \pm 2.9$ & $99.1 \pm 2.7^{*}$ & $42.8 \pm 2.4^{\#}$ & $61.4 \pm 1.9^{* \#}$ \\
\hline
\end{tabular}

Values are presented as mean \pm SD. $n=8$ for each group. BP, blood pressure. AGEs, advanced glycation end products. AG, aminoguanidine.

* $P<0.05$ vs. control.

${ }^{\#} P<0.05$ vs. diabetic group (DM).

doi:10.1371/journal.pone.0142865.t001 
model. We here only focus on the representative channel types that were reported to be involved in vasodilation in our previous studies $[5,6]$. Future studies will examine the changes of other VSMC $\mathrm{K}_{\mathrm{v}}$ channels in diabetes-induced vascular dysfunction. Second, the relevance of our findings is limited in the specificity of the inhibitors. Although AG is the most extensively studied inhibitor of AGEs formation, and rigorous control experiments were performed, genetic approaches will still be required to confirm the effect of AGEs/RAGE axis in $\mathrm{K}_{\mathrm{v}}$ impairment.

\section{Conclusions}

AGEs impair $\mathrm{K}_{\mathrm{v}}$ channels-mediated coronary vasodilation in diabetic rats. Our study demonstrates for the first time that high glucose-stimulated excessive AGEs impair $\mathrm{K}_{\mathrm{v}}$ channels in VSMCs, and supports a role for $\mathrm{K}_{\mathrm{v}}$ channels in the regulation of vascular function in diabetic rats. These results may provide a novel insight into the mechanisms of diabetic coronary dysfunction, and have clinical implications for the treatment of vascular complications in diabetic patients.

\section{Acknowledgments}

The authors thank Hua Wei (School of Basic Medical Sciences, Capital Medical University) for technical supports.

\section{Author Contributions}

Conceived and designed the experiments: WS WL H. Li. Performed the experiments: WS H. Liu HH. Analyzed the data: HC. Contributed reagents/materials/analysis tools: H. Liu HH HC. Wrote the paper: WS WL H. Li.

\section{References}

1. Soro-Paavonen A, Zhang WZ, Venardos K, Coughlan MT, Harris E, Tong DC, et al. Advanced glycation end-products induce vascular dysfunction via resistance to nitric oxide and suppression of endothelial nitric oxide synthase. J Hypertens. 2010; 28(4):780-8. Epub 2010/02/27. doi: 10.1097/HJH. Ob013e328335043e PMID: 20186099.

2. Horiuchi T, Dietrich HH, Hongo K, Dacey RG Jr. Mechanism of extracellular K+-induced local and conducted responses in cerebral penetrating arterioles. Stroke. 2002; 33(11):2692-9. Epub 2002/11/02. PMID: 12411663.

3. Miura H, Wachtel RE, Loberiza FR Jr., Saito T, Miura M, Nicolosi AC, et al. Diabetes mellitus impairs vasodilation to hypoxia in human coronary arterioles: reduced activity of ATP-sensitive potassium channels. Circ Res. 2003; 92(2):151-8. Epub 2003/02/08. PMID: 12574142.

4. Jackson WF. Potassium channels in the peripheral microcirculation. Microcirculation. 2005; 12(1):11327. Epub 2005/04/05. doi: 10.1080/10739680590896072 PMID: 15804979; PubMed Central PMCID: PMC1405752.

5. Li H, Chai Q, Gutterman DD, Liu Y. Elevated glucose impairs cAMP-mediated dilation by reducing Kv channel activity in rat small coronary smooth muscle cells. Am J Physiol Heart Circ Physiol. 2003; 285 (3):H1213-9. Epub 2003/05/24. doi: 10.1152/ajpheart.00226.2003 PMID: 12763748.

6. Li H, Gutterman DD, Rusch NJ, Bubolz A, Liu Y. Nitration and functional loss of voltage-gated K+ channels in rat coronary microvessels exposed to high glucose. Diabetes. 2004; 53(9):2436-42. Epub 2004/08/28. PMID: 15331556.

7. Pinterova M, Behuliak M, Kunes J, Zicha J. Involvement of BKCa and KV potassium channels in cAMP-induced vasodilatation: their insufficient function in genetic hypertension. Physiol Res. 2014; 63 (3):275-85. Epub 2014/01/09. PMID: 24397812.

8. Korovkina VP, England SK. Detection and implications of potassium channel alterations. Vascul Pharmacol. 2002; 38(1):3-12. Epub 2002/10/16. PMID: 12378820. 
9. Lv Y, Tang LL, Wei JK, Xu XF, Gu W, Fu LC, et al. Decreased Kv1.5 expression in intrauterine growth retardation rats with exaggerated pulmonary hypertension. Am J Physiol Lung Cell Mol Physiol. 2013; 305(11):L856-65. Epub 2013/10/01. doi: 10.1152/ajplung.00179.2013 PMID: 24077947.

10. Joseph BK, Thakali KM, Moore CL, Rhee SW. Ion channel remodeling in vascular smooth muscle during hypertension: Implications for novel therapeutic approaches. Pharmacol Res. 2013; 70(1):126-38. Epub 2013/02/05. doi: 10.1016/j.phrs.2013.01.008 PMID: 23376354; PubMed Central PMCID: PMC3607210.

11. Bubolz AH, Li H, Wu Q, Liu Y. Enhanced oxidative stress impairs cAMP-mediated dilation by reducing $\mathrm{Kv}$ channel function in small coronary arteries of diabetic rats. Am J Physiol Heart Circ Physiol. 2005; 289(5):H1873-80. Epub 2005/06/07. doi: 10.1152/ajpheart.00357.2005 PMID: 15937095.

12. Hegab Z, Gibbons S, Neyses L, Mamas MA. Role of advanced glycation end products in cardiovascular disease. World J Cardiol. 2012; 4(4):90-102. Epub 2012/05/05. doi: 10.4330/wjc.v4.i4.90 PMID: 22558488; PubMed Central PMCID: PMC3342583.

13. Gao X, Zhang H, Schmidt AM, Zhang $C$. AGE/RAGE produces endothelial dysfunction in coronary arterioles in type 2 diabetic mice. Am J Physiol Heart Circ Physiol. 2008; 295(2):H491-8. Epub 2008/06/10. doi: 10.1152/ajpheart.00464.2008 PMID: 18539754; PubMed Central PMCID: PMC2519223.

14. Su J, Lucchesi PA, Gonzalez-Villalobos RA, Palen DI, Rezk BM, Suzuki Y, et al. Role of advanced glycation end products with oxidative stress in resistance artery dysfunction in type 2 diabetic mice. Arterioscler Thromb Vasc Biol. 2008; 28(8):1432-8. Epub 2008/05/17. doi: 10.1161/atvbaha.108.167205 PMID: 18483403; PubMed Central PMCID: PMC2755261.

15. Petrica L, Vlad A, Gluhovschi G, Gadalean F, Dumitrascu V, Vlad D, et al. Glycated peptides are associated with the variability of endothelial dysfunction in the cerebral vessels and the kidney in type 2 diabetes mellitus patients: a cross-sectional study. J Diabetes Complications. 2015; 29(2):230-7. Epub 2014/12/17. doi: 10.1016/j.jdiacomp.2014.11.014 PMID: 25511877.

16. Genuth S, Sun W, Cleary P, Gao X, Sell DR, Lachin J, et al. Skin advanced glycation end products glucosepane and methylglyoxal hydroimidazolone are independently associated with long-term microvascular complication progression of type 1 diabetes. Diabetes. 2015; 64(1):266-78. Epub 2014/09/05. doi: 10.2337/db14-0215 PMID: 25187362; PubMed Central PMCID: PMC4274803.

17. Lan KC, Chiu CY, Kao CW, Huang KH, Wang CC, Huang KT, et al. Advanced glycation end-products induce apoptosis in pancreatic islet endothelial cells via NF-kappaB-activated cyclooxygenase-2/prostaglandin E2 up-regulation. PLoS One. 2015; 10(4):e0124418. Epub 2015/04/22. doi: 10.1371/journal. pone.0124418 PMID: 25898207; PubMed Central PMCID: PMC4405342.

18. Wei Q, Ren X, Jiang Y, Jin H, Liu N, Li J. Advanced glycation end products accelerate rat vascular calcification through RAGE/oxidative stress. BMC Cardiovasc Disord. 2013; 13:13. Epub 2013/03/19. doi: 10.1186/1471-2261-13-13 PMID: 23497312; PubMed Central PMCID: PMC3626911.

19. Chang KC, Tseng CD, Wu MS, Liang JT, Tsai MS, Cho YL, et al. Aminoguanidine prevents arterial stiffening in a new rat model of type 2 diabetes. Eur J Clin Invest. 2006; 36(8):528-35. Epub 2006/08/09. doi: 10.1111/j.1365-2362.2006.01672.x PMID: 16893374.

20. Ma C, Zhang Y, Li YQ, Chen C, Cai W, Zeng YL. The Role of PPARgamma in Advanced Glycation End Products-Induced Inflammatory Response in Human Chondrocytes. PLoS One. 2015; 10(5): e0125776. Epub 2015/05/30. doi: 10.1371/journal.pone.0125776 PMID: 26024533; PubMed Central PMCID: PMC4449199.

21. Jackson WF, Huebner JM, Rusch NJ. Enzymatic isolation and characterization of single vascular smooth muscle cells from cremasteric arterioles. Microcirculation. 1997; 4(1):35-50. Epub 1997/03/01. PMID: 9110282.

22. Di BB, Li HW, Li WP, Shen XH, Sun ZJ, Wu X. Pioglitazone inhibits high glucose-induced expression of receptor for advanced glycation end products in coronary artery smooth muscle cells. Mol Med Rep. 2015; 11(4):2601-7. Epub 2014/12/20. doi: 10.3892/mmr.2014.3113 PMID: 25523934.

23. Shen X, Li H, Li W, Wu X, Ding X. Pioglitazone prevents hyperglycemia induced decrease of AdipoR1 and AdipoR2 in coronary arteries and coronary VSMCs. Mol Cell Endocrinol. 2012; 363(1-2):27-35. Epub 2012/07/24. doi: 10.1016/j.mce.2012.07.005 PMID: 22820128.

24. Rajasekar $\mathrm{P}$, Anuradha CV. L-Carnitine inhibits protein glycation in vitro and in vivo: evidence for a role in diabetic management. Acta Diabetol. 2007; 44(2):83-90. Epub 2007/05/29. doi: 10.1007/s00592007-0247-5 PMID: 17530472.

25. de Oliveira Silva C, Delbosc S, Arais C, Monnier L, Cristol JP, Pares-Herbute N. Modulation of CD36 protein expression by AGEs and insulin in aortic VSMCs from diabetic and non-diabetic rats. Nutr Metab Cardiovasc Dis. 2008; 18(1):23-30. Epub 2006/11/28. doi: 10.1016/j.numecd.2006.07.008 PMID: 17127041 
26. Wang H, Li H, Jiang X, Shi W, Shen Z, Li M. Hepcidin is directly regulated by insulin and plays an important role in iron overload in streptozotocin-induced diabetic rats. Diabetes. 2014; 63(5):1506-18. Epub 2014/01/01. doi: 10.2337/db13-1195 PMID: 24379355.

27. Qian C, Zhu C, Yu W, Jiang X, Zhang F. High-Fat Diet/Low-Dose Streptozotocin-Induced Type 2 Diabetes in Rats Impacts Osteogenesis and Wnt Signaling in Bone Marrow Stromal Cells. PLoS One. 2015; 10(8):e0136390. Epub 2015/08/22. doi: 10.1371/journal.pone.0136390 PMID: 26296196; PubMed Central PMCID: PMC4546646.

28. Garcia-Morales V, Cuinas A, Elies J, Campos-Toimil M. PKA and Epac activation mediates cAMPinduced vasorelaxation by increasing endothelial NO production. Vascul Pharmacol. 2014; 60(3):95101. Epub 2014/01/29. doi: 10.1016/j.vph.2014.01.004 PMID: 24469067.

29. Su W, Wang $\mathrm{P}$, Chen $\mathrm{H}, \mathrm{Li} \mathrm{H}$. Role of protein kinase $\mathrm{C}$ beta(2) in relaxin-mediated inhibition of cardiac fibrosis. J Endocrinol Invest. 2014; 37(6):559-64. Epub 2014/04/15. doi: 10.1007/s40618-014-0068-7 PMID: 24729283.

30. Heaps CL, Tharp DL, Bowles DK. Hypercholesterolemia abolishes voltage-dependent K+ channel contribution to adenosine-mediated relaxation in porcine coronary arterioles. Am J Physiol Heart Circ Physiol. 2005; 288(2):H568-76. Epub 2004/10/02. doi: 10.1152/ajpheart.00157.2004 PMID: 15458946.

31. Zhao LM, Wang Y, Ma XZ, Wang NP, Deng XL. Advanced glycation end products impair K(Ca)3.1- and $\mathrm{K}(\mathrm{Ca}) 2.3-m e d i a t e d$ vasodilatation via oxidative stress in rat mesenteric arteries. Pflugers Arch. 2014; 466(2):307-17. Epub 2013/07/23. doi: 10.1007/s00424-013-1324-y PMID: 23873353.

32. Henrion D. Pressure and flow-dependent tone in resistance arteries. Role of myogenic tone. Arch Mal Coeur Vaiss. 2005; 98(9):913-21. Epub 2005/10/20. PMID: 16231579.

33. Kajikawa M, Nakashima A, Fujimura N, Maruhashi T, Iwamoto Y, Iwamoto A, et al. Ratio of serum levels of AGEs to soluble form of RAGE is a predictor of endothelial function. Diabetes Care. 2015; 38 (1):119-25. Epub 2014/10/23. doi: 10.2337/dc14-1435 PMID: 25336748.

34. McVicar CM, Ward M, Colhoun LM, Guduric-Fuchs J, Bierhaus A, Fleming T, et al. Role of the receptor for advanced glycation endproducts (RAGE) in retinal vasodegenerative pathology during diabetes in mice. Diabetologia. 2015; 58(5):1129-37. Epub 2015/02/18. doi: 10.1007/s00125-015-3523-x PMID: 25687235; PubMed Central PMCID: PMC4392170.

35. Serban AI, Stanca L, Geicu OI, Munteanu MC, Costache M, Dinischiotu A. Extracellular matrix is modulated in advanced glycation end products milieu via a RAGE receptor dependent pathway boosted by transforming growth factor-beta1 RAGE. J Diabetes. 2015; 7(1):114-24. Epub 2014/03/29. doi: 10. 1111/1753-0407.12154 PMID: 24666836.

36. Matsui T, Oda E, Higashimoto Y, Yamagishi SI. Glyceraldehyde-derived pyridinium (GLAP) evokes oxidative stress and inflammatory and thrombogenic reactions in endothelial cells via the interaction with RAGE. Cardiovasc Diabetol. 2015; 14(1):1. Epub 2015/01/15. doi: 10.1186/s12933-014-0162-3 PMID: 25582325; PubMed Central PMCID: PMC4299541.

37. Lander HM, Tauras JM, Ogiste JS, Hori O, Moss RA, Schmidt AM. Activation of the receptor for advanced glycation end products triggers a p21(ras)-dependent mitogen-activated protein kinase pathway regulated by oxidant stress. J Biol Chem. 1997; 272(28):17810-4. Epub 1997/07/11. PMID: 9211935.

38. Bierhaus A, Humpert PM, Morcos M, Wendt T, Chavakis T, Arnold B, et al. Understanding RAGE, the receptor for advanced glycation end products. J Mol Med (Berl). 2005; 83(11):876-86. Epub 2005/09/ 01. doi: 10.1007/s00109-005-0688-7 PMID: 16133426.

39. Basta G, Lazzerini G, Massaro M, Simoncini T, Tanganelli P, Fu C, et al. Advanced glycation end products activate endothelium through signal-transduction receptor RAGE: a mechanism for amplification of inflammatory responses. Circulation. 2002; 105(7):816-22. Epub 2002/02/21. PMID: 11854121.

40. Elvira B, Warsi J, Munoz C, Lang F. SPAK and OSR1 sensitivity of voltage-gated K+ channel Kv1.5. J Membr Biol. 2015; 248(1):59-66. Epub 2014/10/16. doi: 10.1007/s00232-014-9741-1 PMID: 25315612 .

41. Chapalamadugu KC, Panguluri SK, Bennett ES, Kolliputi N, Tipparaju SM. High level of oxygen treatment causes cardiotoxicity with arrhythmias and redox modulation. Toxicol Appl Pharmacol. 2015; 282 (1):100-7. Epub 2014/12/03. doi: 10.1016/j.taap.2014.10.019 PMID: 25447406; PubMed Central PMCID: PMC4426884.

42. Kurokawa S, Niwano S, Niwano H, Murakami M, Ishikawa S, Masaki Y, et al. Cardiomyocyte-derived mitochondrial superoxide causes myocardial electrical remodeling by downregulating potassium channels and related molecules. Circ J. 2014; 78(8):1950-9. Epub 2014/05/27. PMID: 24859499.

43. Omae T, Nagaoka T, Tanano I, Yoshida A. Pioglitazone, a peroxisome proliferator-activated receptorgamma agonist, induces dilation of isolated porcine retinal arterioles: role of nitric oxide and potassium channels. Invest Ophthalmol Vis Sci. 2011; 52(9):6749-56. Epub 2011/07/16. doi: 10.1167/iovs.106826 PMID: 21757589. 
44. Chen YJ, Sheu ML, Tsai KS, Yang RS, Liu SH. Advanced glycation end products induce peroxisome proliferator-activated receptor gamma down-regulation-related inflammatory signals in human chondrocytes via Toll-like receptor-4 and receptor for advanced glycation end products. PLoS One. 2013; 8(6): e66611. Epub 2013/06/19. doi: 10.1371/journal.pone.0066611 PMID: 23776688; PubMed Central PMCID: PMC3680452.

45. Ohya S, Tanaka M, Watanabe M, Maizumi Y. Diverse expression of delayed rectifier K+ channel subtype transcripts in several types of smooth muscles of the rat. J Smooth Muscle Res. 2000; 36(3):10115. Epub 2000/11/22. PMID: 11086882. 